\title{
Morangos silvestres: imagens-tempo de um aprendizado
}

\author{
Wild strawberries: time-images of an apprenticeship \\ http://dx.doi.org/10.5007/2178-4582.2017v51n1p021
}

\section{Tania Mara Galli Fonseca}

Universidade Federal do Rio Grande do Sul, Porto Alegre/RS, Brasil

\begin{abstract}
Através do filme Morangos Silvestres (1957) de Ingmar Bergman, este texto se dedica a analisar suas imagens-tempo. Estas aproximam o cinema da realidade do pensamento, tendo a função de levar o olho à função de vidência, pois os elementos da imagem entram em relações que fazem com que a imagem inteira deva ser "lida" não menos que vista, legível tanto quanto visível. O mundo aparece para ser visto e lido, como literalidade. Cinema mais perto de uma leitura do que de uma percepção, cinema que nos leva ao caminho dos signos, que nos torna decifradores, nos fazendo recuar do reconhecimento automático e habitual. Uma montagem que propõe transtornos às percepções e ações do espectador, porque faz irromper um elemento novo que impede a percepção de se prolongar em ação.
\end{abstract}

Palavras-Chave: imagem-tempo; signo; aprendizado; cinema vidente.
Through a study of Ingmar Bergman's film Wild Strawberries (1957), this text seeks to analyze its time-images. These bring the cinema of the real closer to thought and also have the purpose of exercising the eye's function as seer since the elements of the image relate in such a way that they must be "read" as much as seen. Legible as much as visible, the world presents itself to be seen and read as if it were "literalness". This is a cinema which draws closer to reading than to perception, a cinema which takes us down the path of signs, which transforms us into decipherers, and which makes us repudiate automatic and habitual recognitions. It is a cinema where the montage proposes encumbrances to the spectator's perceptions and its extensions into action by introducing a new element which impedes perception from spreading into the form of action.

Keywords: time-image; sign; apprenticeship; cinema of the seer.

\section{O cinema-visionário das imagens-tempo}

Morangos Silvestres (Smultronstället), de Ingmar Bergman, foi produzido em 1957, sendo considerado uma obra prima do cineasta. O filme foi premiado com o Urso de Ouro de Berlim e também com o Globo de Ouro, tendo sido indicado para o Oscar por seu roteiro. Sumariamente, sua narrativa é a seguinte: no caminho da Universidade de Lund, onde receberá um prêmio pelos 50 anos de carreira, o professor de medicina Isak Borg, interpretado pelo cineasta Victor Sjöström, relembra momentos de sua vida, temendo a morte que se aproxima. Gostaríamos de situar tal filme no âmbito do cinema pósguerra, época em que cineastas como Fellini, Visconti, De Sica, Rossellini, Antonioni, Godard, dentre outros, buscavam novos modos de filmagem de modo a colocar em crise o chamado cinema de ação então vigente. A crise das imagens-movimento deste último levou os cineastas a perpetrarem uma ousadia estética que, na verdade, aproximou o cinema da realidade do pensamento. A nova montagem propunha transtornos às percepções e ações do espectador, porque fazia irromper um elemento novo que impedia a percepção de se pro- 
longar em ação. Fazia ascender situações óticas e sonoras que se distinguiam das situações sensório-motoras da imagem-ação do antigo realismo. Nesta nova situação, a personagem torna-se espectadora e, por mais que se mova, a situação em que está extravasa de todos os lados suas capacidades motoras e lhe faz ver e ouvir o que não é mais passível de uma resposta ou ação. A nova imagem surge, pois, a partir do afrouxamento dos vínculos sensório-motores, sendo afetadas por uma certa impotência motora que, entretanto, aumenta a aptidão para ver e ouvir. Escapa, subitamente, às leis do esquematismo dos hábitos sensoriais e perceptivos, revelando as situações em sua nudez e crueza que as tornam até insuportáveis, dando-lhes aspecto de sonho ou de pesadelo. Agora, não somente o espectador mas também os protagonistas investem os meios e os objetos pelo olhar, fazem nascer a paixão e a ação numa vida cotidiana preexistente. Produzem uma espécie de inventário e, mesmo não se tratando mais de um prolongamento motor, estabelecem, antes, uma relação onírica, por meio dos órgãos dos sentidos libertos. Poder-se-ia dizer que a ação flutua na situação, mais do que a arremata ou encerra. Trata-se de um esteticismo visionário com uma espantosa potência para explorar a banalidade cotidiana e também situações extremas. Tal se faz possível pelas perturbações que são introduzidas nas cenas, que as afetam, soltam, desequilibram. Tudo se faz como se real e imaginário corressem um atrás do outro, se refletissem um no outro em torno de um ponto de indiscernibilidade: produz-se o real através de uma descrição que ora apaga ou destrói a realidade dos objetos e dos seres que entram no imaginário, mas que por outro, faz surgir toda a realidade que o imaginário cria pela palavra e pela visão. Imaginário e real tornam-se, eles próprios, indiscerníveis em suas conversões e passagens. Tanto o neorrealismo italiano como a nouvelle-vague francesa criam e impulsionam a ascensão das situações óticas e sonoras que lançam para ligações de um novo tipo, que não são mais sensório-motoras e põem os sentidos liberados em relação direta com o tempo, com o pensamento. Tal é o prolongamento essencial que ocorre: o de tornar sensíveis o tempo e o pensamento, torná-los visíveis e sonoros, possibilitando apreender algo intolerável, insuportável que, por sua vez, não se refere a uma agressão ou violência aumentada. Trata-se sempre de algo poderoso demais ou injusto demais que nos excede em nossas ordinárias capacidades sensoriais e motoras. É assim, que este "grande demais para nós" torna-se também uma revelação, uma iluminação, como um terceiro olho. $\mathrm{O}$ importante desse cinema é que a personagem ou o espectador, ou os dois juntos, se tornem visionários, que se vejam imersos na função de vidência, ao mesmo tempo fantasma e constatação, crítica e compaixão.

A pedagogia e a política implícitas neste cinema-vidência se relacionam à potência para vir quebrar nossos clichês pelos quais percebemos o mundo e a nós mesmos sempre de forma subtraída, uma vez que filtramos nossa visão 
apenas nos aspectos que nos interessam. Não damos ao mundo e aos seres o direito de sua literalidade, de aparecerem sem metáforas, em si mesmos, em seu excesso. Os filtros de nossa moral nos mantêm tão somente no plano das conveniências e do justificável, não nos permitindo ousar para além do bem e do mal, num sentido extramoral. Nossas pré-imagens encobrem e induzem o que vemos, nos dão apenas a noção indireta do tempo. No cinema-tempo de que falamos, e no qual Morangos Silvestres se insere, ocorre a reversão que não faz mais do tempo a medida do movimento, mas do movimento a perspectiva do tempo, o olho acedendo a uma função de vidência, as imagens inteiras devendo ser lidas não menos que vistas, legíveis tanto quanto visíveis. Agora, a câmera se define mais pelos movimentos que é capaz de seguir ou realizar, mas pelas relações mentais nas quais é capaz de entrar. Torna-se questionante, provocante, pensante, experimental. Trata-se, aqui, de tornar a matéria em sinalética, ou seja, introduzir-lhe a legibilidade dos signos. Torná-la, assim, menos evidente, afastada do já conhecido e do facilmente representável, torná-la enigma a ser decifrado, torná-la expressão da vida que a move, do tempo que a forma e deforma, cria e recria. Falamos, aqui, de uma desistência em prolongar nossa percepção onde não podemos mais prolongá-la, falamos de uma reversão de sutis movimentos que retornam ao objeto para enfatizar-lhe certos contornos, extrair-lhe certos traços, falamos em alçar a visão a um diferente plano, não mais orgânico, em que o que vemos passa por uma descrição que "apaga" o objeto concreto, escolhe dele apenas alguns traços, sempre com o risco de dar lugar a outras descrições, sempre provisórias, deslocadas ou substituíveis. As imagens ótico-sonoras são sempre sóbrias, raras, elas retêm apenas meros pontos, elevam a coisa a uma singularidade essencial, descrevem o inesgotável, pertencem ao plano das durações. Seu essencial é que unem o atual ao virtual, fazendo com que um corra atrás do outro num plano que corresponde a uma zona de lembranças, de sonhos ou de pensamentos: a cada vez é um plano ou um circuito de modo que a coisa passa por uma infinidade de planos que correspondem às suas próprias camadas ou aspectos. Neste ponto, não há mais imagens sensório-motoras com seus prolongamentos e cadeia associativa, mas vínculos circulares complexos entre imagens óticas e sonoras de um lado, e de outro, imagens vindas do tempo ou do pensamento, que constituem a alma e o corpo da ilha. Assim, a imagem atual encadeia-se a uma imagem virtual e forma com ela um circuito. É assim que as lembranças assumem um sentido completamente novo: elas se tornam um meio da produção de novos sentidos, já não são motor ou material, mas temporal e espiritual: tornam-se o que se acrescenta à matéria, tiram proveito do espaço vazio entre ação e reação, fazem circunvoluções, novas ligações entre o que se vê e o que se sente, repousam num tempo denso, que não passa, mas que dura e insiste. É o flash-back, na linguagem do cinema, que expressa esta relação, 
uma vez que é um circuito que vai do presente ao passado e depois remete de volta ao presente. Não se trata de um momento de explicação. Ao contrário, é o momento de um segredo, de uma fragmentação, de constantes bifurcações que rompem com a lógica da causalidade. Agora não é mais o espaço que se bifurca, mas sim o tempo, abarcando múltiplas possibilidades. Em cada flash-back, bifurcações do tempo, cruzamentos, forquilhas, nova ruptura de causalidade, um conjunto de relações não-lineares. Não há, de fato, nem linha reta, nem círculo que se fecha. Não há dissipação do enigma, mas sim a remissão a outros enigmas ainda mais profundos. Trata-se de uma história que só pode ser contada no passado. O que se passou? Como chegamos a isso? Estas são as perguntas que talvez Borg esteja fazendo quando por sua voz em off é quem relata o que se passou. A voz como memória e em off enquadra o flash-back. Neste ponto, seria importante dizer que em vez de uma memória constituída, como função do passado, assiste-se, agora, o nascimento da memória como função do futuro que retém o que se passa para dele fazer o objeto por vir da outra memória. A memória não poderia evocar e contar o passado se não se tivesse constituído no momento em que o passado ainda era presente, portanto, um objeto por vir. É no presente que se faz uma memória, para ela servir no futuro, quando o presente for passado. É essa memória do presente que faz se comunicarem os circuitos atual e virtual. Bergson (1990) sempre lembrava que a imagem-lembrança não devia a si mesma a sua marca de passado, quer dizer a marca de virtualidade que ela encarna. Para o filósofo, se a imagem se faz imagem-lembrança é somente na medida em que foi procurar uma lembrança pura lá onde esta se encontrava, pura virtualidade contida nas zonas escondidas do passado. "Imaginar não é lembrar", ele nos diz.

Sem dúvida, uma lembrança, à medida que se atualiza, tende a viver em uma imagem, mas a recíproca não é verdadeira e uma imagem pura e simples só levará ao passado se foi mesmo no passado que foi procurada, seguindo o progresso contínuo que a trouxe da obscuridade à luz. (BERGSON, 1990, p. 70).

A imagem-lembrança não é virtual, ela atualiza por sua conta uma virtualidade, ela não nos restitui o passado, mas somente representa o antigo presente que o passado foi. É assim, que podemos dizer que o cinema-tempo de que falamos separa-se tanto do reconhecimento motor quanto do reconhecimento memorial. Nele, o tempo conquista uma liberdade profunda, parecendo que à impotência motora do personagem corresponde agora uma mobilização total e anárquica do passado.

E qual seria a função do sonho, neste tipo de filme-tempo? Bergson (1990), o filósofo da memória, já nos mostrava que a pessoa que dorme não 
está fechada às sensações do mundo exterior e interior. Ela se encontra em relação não com imagens-lembranças, mas com lençóis de passado, fluídos e maleáveis que se contentam com um ajuste bem frouxo e flutuante. Para ele, o sonho representa o mais vasto circuito aparente, sendo o invólucro extremo de todos os circuitos. Já não é o vínculo sensório-motor da imagem-ação no reconhecimento habitual; trata-se, antes, da ligação fraca e desagregadora de uma sensação ótica ou sonora a uma imagem sensorial qualquer. As percepções de uma pessoa que dorme subsistem, porém, no estado difuso de uma nuvem de sensações atuais, exteriores e interiores, que não são apreendidas por si mesmas, escapando à consciência. Assim, o sonho não se constitui em uma metáfora, mas numa série de anamorfoses que traçam um circuito muito grande, um devir, que pode prosseguir ao infinito.

\section{Um aprendizado pelos signos}

Após estas considerações de cunho conceitual, seria preciso dizer que não fora este o caminho que eu havia iniciado, quando me debrucei a escrever este texto. Na verdade, fui levada a ele por minhas insuficiências expressivas para dar conta das afecções e ideias disparadas pelo mundo do filme Morangos Silvestres. Precisei dar um contorno ao meu ímpeto inicial de vir a desenvolver duas idéias que me obsedaram após ver e rever o filme. Pensei, intuitivamente, que deveria desenvolver exatamente o que coloquei como título deste artigo: Morangos Silvestres: um aprendizado através de imagens-tempo. A ideia de aprendizado provém de meus atuais estudos nos quais encontro o conceito de recherche, inspirado na obra de Proust (2004). La recherche trata-se de virmos saber, após os fatos acontecidos, o que se passou, o que aconteceu, enfim, o aprendizado de uma vida, o legado daquilo que foi possível viver, percorrido que foi pelo tempo perdido e reinventado agora, quem sabe, num tempo redescoberto. Em Proust, la recherche descreve as transformações, a série de anamorfoses que o tempo impõe aos sujeitos e aos ambientes que lhes são associados. Trata-se, assim, do registro das variações contínuas sofridas pelos corpos em seu processo de existir; deste modo, somos defrontados exatamente com um processo, algo que transcorre, que se move em direção a devires insuspeitados, desenhando formas e as desfazendo incessantemente. Somente pode-se ter percepção de tais variações após elas terem acontecido. No instante de sua ocorrência, de seu acontecimento, elas nos escapam e se fazem registro, deixam-nos vestígios, como faces mutantes sobre um rosto que se torna, assim, superfície de inscrição do tempo intempestivo do acontecimento. La recherche junta-se ao aprender, uma vez que coloca o sujeito em um recuo do que passou, situando-o como um observador atento das variações, como um duplo que ao mesmo tempo que viveu a situação, agora a transforma em 
experiência passível de ser dita e colocada em imagens. Não se trata de uma recuperação de um passado passado. Refere-se a um novo sentido que salta quando a memória se afunda nos lençóis do tempo, penetra o extremo de seu circuito, ali, onde habita o presente daquele passado relembrado, onde formigam as virtualidades de uma memória involuntária que só advém por assalto ao atual presente, tornando-o outra coisa que ultrapassa sua realidade física/ material e significada. Agora, no procedimento da busca deste tempo perdido, redescobre-se o outro dos mundos, o frêmito que sustentou a criação de tal ou qual paisagem, que já não pertence, a esta altura ao homem, mas ao seu resto de não-homem. Caberia dizer que resto, aqui, não se refere ao lixo ou ao que foi refugado. Resto compreende o outro daquele momento do acontecimento, ao passado que esteve colado à realização daquele momento presente que agora se afundou como passado. Resto de não-homem significaria, em nosso entendimento, a recuperação das imagens do tempo, não mais motoras, mas ainda ativas e em potência, dirigidas ao futuro, ao devir.

Escrever, para Proust, compara-se ao fazer filmes para estes cineastas do tempo. Trata-se de uma obsessão em que, mesmo após as catástrofes, leva a estar à altura de saber das múltiplas tentativas do desejo em dar formas diversas à vida de cada personagem. A arte de Proust, como a de Bergman e outros, não se refere a uma busca do passado tal como foi vivido. Nela, aqueles conceitos expostos na seção anterior impregnam-se como uma prática desesperante de redescoberta dos elementos e dos nexos que ficaram imersos na zona noturna e onírica dos signos. São artistas obsedados pela tradução do mundo e de seus seres em sua literalidade. Artistas do tempo, do aprendizado da memória, não mais da memória ruminativa e reapresentada, mas de uma memória ontológica, capaz de criar mundos e reencantar o tempo presente. Desejam um além do homem, um além daquele homem sensorial, simples, consciente, reativo, pragmático e utilitário. Eles infundem à matéria elementos diáfanos, incorporais, virtuais, revertendo o vivido em outra coisa vívida, injetam, em suas descrições tempo, pensamento e vida para que violentem nosso cotidiano amortecido pelas costumeiras ilusões. Levando-nos ao plano dos incorporais inconscientes, eles projetam seus martelos contra as ilusões forjadas pela razão reta e lógica. Querem o não-homem do homem, o não-mundo do mundo, o outro de si mesmos. Com eles, estamos nos círculos do Outro, tornamo-nos estrangeiros aos valores que têm nos sustentado, habitamos um deserto desorientador, praticamos um esquecimento daquilo que temos sido e em que estamos nos tornando, devimos qualquer outra coisa que, mesmo podendo ser minúscula e imperceptível, ainda assim se faz potente para a nossa alegria de estar vivos. 


\section{A trama e o drama}

Vemos o professor Borg em seu gabinete, cercado de objetos que, como signos, traduzem sua posição social, seu estilo de vida, enfim, nos introduzem em seu mundo subjetivo: organizado, confortável, esteticamente harmônico e tradicional. Signos de mundanidade, como nos diria Deleuze (1987), que não nos forçam a pensar: apenas nos fazem ver e reconhecer. A voz em off do próprio personagem já nos oferece uma pista para que saibamos que ele é ao mesmo tempo o protagonista e o narrador da história que iremos acompanhar. Um duplo, neste momento, se cria: Borg vê-se/ lê-se, enquanto se narra a nós. É visível e legível a si, está dentro e fora da cena, ocupa o campo e o extracampo, como a mostrar duas condições: a de seu corpo, ocupando o espaço e a de sua mente habitando o tempo. Corpo-espírito, corpo-pensamento ilustrariam perfeitamente esta fusão do que vemos e do que é dito, e já podemos observar uma grande disjunção entre estas duas operações. Embora esteja às vésperas de receber um importante prêmio acadêmico, o personagem expressa seu aborrecimento com esta glória e sucesso: diz encontrar-se, de alguma maneira, enfastiado com o mundo social, quase que indiferente ao mesmo e às suas pompas, apontando-nos para uma outra dimensão de seus afetos: sente-se velho e, portanto, aguça-o o temor da morte e este avulta-lhe uma sensação de solidão e de um tempo em que tudo já estaria perdido; vive, desta forma, um "tarde demais" para outra vida. Sente-se aprisionado na vida que viveu, tão racionalizada quanto formal, afastada, talvez, de outras forças que a teriam tornado mais vívida e afetiva. Sinto-me obrigada, neste ponto, a ceder à tentação de dizer que Borg expressa, neste momento, a idéia de um fracasso, de algo que não tivesse valido a pena, embora tivesse sido bem sucedido no plano profissional e mundano a ponto de merecer homenagem e aplausos. Borg renuncia aos signos mundanos que lhe conferem poder. Esta questão se agudiza, entretanto, através de um sonho. Neste, desvela-se a sua desorientação, completamente assintônica com o momento de sua realidade cotidiana, a de um acadêmico premiado e homenageado. Os relógios que acessa não possuem ponteiros. Deixaram de funcionar na contagem dos instantes, evidenciando sua parada em um certo ponto indiscernível: Borg já não sabe em que dia está, em que momento se situa na forquilha de um tempo embaralhado. Da mesma forma, a cena se passa na encruzilhada de uma rua deserta por onde assoma uma carruagem funerária que leva um morto. Carruagem que perde uma das rodas, "sai dos trilhos" e solavanca. Já não desliza e flui, já não consegue contornar os obstáculos e o caixão que transporta salta ao chão, abrindo-se, deixando que Borg, neste momento, reconheça-se como o morto que está sendo carregado. Trata-se, evidentemente, de um pesadelo em que as imagens apontam não somente para os afetos de morte e solidão de um 
velho, como ainda o mostram desorientado em relação ao espaço e ao tempo. $\mathrm{O}$ peso da consciência da morte produz os desvios, sendo poderoso e grande demais mesmo para o professor experiente e celebrado. Talvez mesmo se pudesse ainda dizer que seus afetos não se reduziriam ao temor à morte, mais do que isso, o relógio sem ponteiros não significaria o vazio da Morte, mas a abertura para o tempo multilinear do Morrer. Não se trata que a personagem subitamente tenha constatado que o tempo passa e que envelhecemos, que tudo há de desaparecer, que a vida é uma quimera, que nada vale a pena, que somos sombras pálidas... A partir deste sonho, Borg se desorganiza e sai de seu tempo controlado e homogêneo, linear e habitual. Vive toda uma aventura íntima que o desapossa de sua vontade, num estado em que os tempos se misturam e a vida ganha um novo relevo. No referido sonho, já não contam os signos mundanos do poder dos saberes e da experiência. Borg mostra-se desamparado e perdido, apenas observa o que vê passar, fazendo retornar sobre si a consciência da inutilidade de seus títulos e talvez de suas próprias atitudes. Desnuda-se diante da extrema consciência de sua possível morte e, mesmo que sobriamente, experimenta este relâmpago como um convite para desviar da programação da viagem que faria. Resolve deslocar-se por si mesmo, de automóvel, através dos locais onde vivera a infância e a juventude. Decide empreender uma viagem aparentemente às avessas, ou seja, do presente ao passado, mas vemos, que é exatamente um novo presente que é produzido, um devir em seus dias atuais, produzido por esta viagem, por esta busca, que, se poderia dizer, pertence a uma natureza imóvel e imemorial.

É nesta viagem que outros personagens entram em cena: os três jovens viajantes, o casal em crise e a mãe do protagonista. As relações entre os personagens com o professor e entre eles próprios vêm carregadas de signos de amor os quais desenham uma pluralidade de mundos. Aqui, seria interessante lembrar que o ser amado sempre aparece como signo que exprime um mundo possível mas desconhecido. $\mathrm{O}$ amado implica, envolve, aprisiona um mundo, que é preciso decifrar. Amar torna-se, assim, em procurar desenvolver esses mundos desconhecidos que permanecem envolvidos no amado. Isto quer dizer que quando amamos, sempre desembocamos em mundos que se formaram sem nós, que se formaram com outras pessoas, onde não somos, de início, senão um objeto como os outros. Os signos do ser amado nos excluem e diferem dos signos mundanos dos quais falávamos acima. São signos mentirosos que não podem se dirigir a nós senão escondendo o que exprimem, isto é, a origem dos mundos desconhecidos, dos pensamentos e das ações que lhes dão sentido. Os signos do amor suscitam o sofrimento de um aprofundamento e, de certa maneira é o que podemos ver em todas as situações do filme que implicam os signos do amor. Da mesma forma, desencadeiam decepções à medida que se desenvelopam, acentuando a percepção da distância que sempre é inevitável 
entre duas pessoas. Sabemos que somos feitos de distâncias, como igualmente reconhecemos que são nas relações amorosas que experimentamos o insuportável do homem, uma vez que as mesmas são marcadas pela questão do Outro, bem como para a nossa impotência de reduzi-lo ao Mesmo ou ao nosso próprio Eu. Relações sempre deslocáveis, interrompidas pela estranheza, que revelam a separação antes do que a unidade das pessoas. Paradoxalmente, isto nos leva a verificar que, do ponto de vista amoroso, coexiste no mais íntimo o mais separado e o que aparece como eminentemente interiorizado, se contagia e associa com um fora de alcance. E talvez seja esta relação de estranheza e também de fracasso que, por sua exorbitância e excesso, se constitua naquilo que nos leva a perseverar quando falamos em viver e amar juntos. Algo que recua e se esquiva como sem horizonte possível e que, contudo, se torna um atrator para novas e outras decifrações.

No filme, desencontros, formalismos, conflitos apontam para a crise das relações entre os sujeitos, seja qual for seu nível de intimidade. As situações triangulares se fazem igualmente recorrentes nos diversos casos, e mesmo quando não evidenciam a presença física de uma terceira pessoa, ainda assim, pela ausência, um outro alguém se coloca entre o par: é o caso de Marianne e seu marido em relação à gravidez, ainda o dos três jovens viajantes e as indefinições relativas à escolha amorosa que irá definir qual será o casal, eu diria ainda que o caso da própria empregada com o professor, que têm como interposta em seu relacionamento a instituição da viuvez e portanto a presença-ausente da esposa falecida, e, ainda, o caso da mãe de Borg, viúva e rígida, resmungona, distante e, sobretudo evitativa e hostil. A situação amorosa triangular efetiva-se de forma drástica na visão que Borg tem quando em visita à casa de sua infância, no canteiro dos morangos silvestres. Ali, é com seu irmão que se dá o triângulo em relação à mulher amada, ficando Borg excluído e em grande sofrimento de ciúmes e dor afetiva. Parece-nos provir do reencontro com os morangos silvestres que se opera esta reminiscência reveladora a Borg que, tal como na conhecida situação da madeleine de Proust (2004), a partir das qualidades deste signo sensível por sua cor e gosto, é lançado para um antigo passado familiar acontecido na residência da infância. As qualidades sensíveis dos morangos silvestres proporcionam a Borg uma alegria e, ao mesmo tempo, tornam-se algo completamente diferente do próprio objeto. Tudo se passa como se as qualidades sensíveis envolvessem a alma de um objeto diferente daquele que ela agora designa. No caso dos morangos silvestres, eles, como signo, parecem-nos envolver, para o protagonista, sua própria infância e juventude bem como as implícitas lidas da busca de amor seja o familiar, seja o conjugal. O casamento e a procriação parecem constituir-se em um horizonte de tais cenas, cujo teor vemos repetido no plano atual da própria viagem que realiza de automóvel. Através das dramatizações efetuadas pelos diversos 
personagens que ocupam o carro, agora, já poderíamos considerar que as cenas pertencem ao grande teatro permanente e incessante, no qual mudam os palcos e os personagens, que estão sempre a encenar, desde seus enredamentos históricos, sociais e afetivos, a grande peça do viver. Seria 'Uma Vida' a personagem principal, vida que ultrapassa a sua restrição à finitude das figuras concretas dos indivíduos, 'uma vida' e seus sentidos, 'uma vida' e seus possíveis a cada vez, em cada um. Tratar-se-ia, nesta perspectiva, da pergunta que Isak Borg estaria se fazendo: o que se passou? como chegamos a isso? A partir deste momento, em que as qualidades sensíveis ou as impressões já encarnam outra coisa que ultrapassa o objeto em que se manifestam, elas já apontam para um nível mais profundo para onde todos os signos convergem. É assim que, para finalizarmos, nos deteremos na última cena do filme, na qual há um lance súbito e chocante, pois ela já está sendo produzida em outro plano que não o de uma memória consciente de um sujeito: a última cena nos lança à dimensão do ser do passado, refere-se a uma memória imemorial, involuntária e incandescente que anima, de certa forma, todas as demais que assistimos. Como nos diria Deleuze (1988), reenquadra o círculo, não o fazendo rimar entre seu começo e seu fim, entretanto. Díspar, ela se ergue como uma nova onda nas oscilações subjetivas de Borg, pois se trata agora não mais de um tarde demais, não mais de um tempo perdido para sempre, revela-se como um tempo redescoberto, tal qual na recherche proustiana que, como exposição de um longo aprendizado, tão longo quanto dure a existência de uma vida singular, abre-se num aceno ao mundo, num aceno ao amor e à receptividade. É certo que poderemos, nesta cena, divisar as ilusões que percorrem os caminhos de uma busca, é certo que nas imagens que a cena mostra ainda resta algo de uma inocência, em que a experiência não foi destruída por uma história de acontecimentos vividos. Ali, se firma a crença no amor conjugal que bem ou mal acreditemos, hoje, desde nosso atual estado de crítica, rege parte dos caminhos do mundo, dirige-os para a realização do triângulo pai, mãe e filho, apontando, ainda nas ilusões de nosso tempo presente, algo edipiano demasiadamente grande, mas que, mesmo assim, reconforta e torna suportável o insuportável. Para finalizar, em minhas palavras, descrevo e procuro analisar algo mais da última cena.

Gostaria, assim, de me referir a este bloco de sensações que me engasgou em especial na última cena que o filme registra: a do narrador-ator a visualizar a imagem de seus pais em uma cena a céu aberto, talvez um piquenique à beira-mar, talvez uma saída aos arredores de sua residência. Nessa cena, Bergman imprime sua força total para nos arrastar em suas imagens-tempo. Acenando ao narrador-ator, seus pais advêm de um distante passado como um jovem casal vivendo a leveza e as alegrias de um dia de felicidade recíproca, acenam ao filho - que está à margem -, dando-nos a perceber sua confiança 
no mundo, um aceno suave de boas vindas ao filho e às paisagens que divisam para o futuro de suas vidas. Uma crença no futuro. Despretensioso, em sua verde juventude, o casal vive os momentos de um dia, deixando passar, em suas imagens, nada de espetacular pela extraordinariedade. Ali, Borg, o filho, os contempla em um cotidiano banal que, entretanto, torna-se marcante pelas intensidades que da cena se desprendem, a ponto de nos deixar sem palavras para traduzir o que sentimos quando a vemos. É certo que se trata de um dia comum, mas, devemos ressaltar que se trata de um momento de passeio, de distração, ou seja, de um momento que somente nasce quando se está disposto a perder tempo, quando se está disposto, portanto, a viver momentos da vida sem a pretensão de objetivos previstos.

Pensamos então nos momentos em que cerramos os olhos às preocupações costumeiras, momentos de esquecimento de nossa finitude em que apenas fruímos o viver junto à natureza e aos nossos amados, deixando escoar os instantes à deriva e em desvio da grelha reguladora e cronometrada. Um passeio, um dia, uma estação, um instante qualquer em que somos surpreendidos pela alegria de estar vivos e de viver juntos. Escolhida para constituir-se como o final do filme, esta cena nos faz saltar para outro plano de percepção, colocando-nos, intensa e radicalmente em um outro do mundo, em um outro do tempo, em um outro de nós mesmos. É assim, que, ao final do filme, já podemos sentir que não estamos mais no mesmo lugar em que estávamos, algo nos arrebatou mesmo que não nos movêssemos, algo entrou em choque com nosso habitual estar. Não gostaria de tomar muito tempo desde esta cena de ápice afetivo. Entretanto, exatamente devido ao fato que a mesma tenha se constituído como culminância para mim, é que ela me toma e, ao mesmo tempo, me dá a mão para que finalize minhas colocações incertas, direcionadas que se tornam para esse instante ótico de especial espessura para minhas afecções. Será bem possível que outras observações, ou melhor, que outros observadores e comentadores não tenham se deixado levar por esta flechada, por este relâmpago que, ao final, tornou-se uma espécie de chave para abrir as portas dos signos imagéticos emitidos por Bergman neste seu maravilhoso filme-tempo. Encontrar a chave da porta, entretanto, não significa encontrar a verdade que se encontra nela encerrada. Refere-se, antes, a alguma perdição na orientação segura em que, andando de olhos fechados, sob o efeito das flechas disparadas e com tremor nas bases, tentamos nos situar em ancoradouros pelos quais possamos tentar adentrar enigmas e silêncios. Trata-se, enfim, de um procedimento metodológico que buscamos e que tem como ponto de partida justamente aquilo que nos fascina por ser grande demais para que se explique de uma vez só e por todas. Por esta cena-chave que elegemos e que nos elegeu, também fizemos uma busca da verdade que já não pode mais ser colocada como a descoberta de um sentido final. Agora, com a chave em mãos, to- 
mando-nos o corpo, seguimos em busca da verdade como uma recherche, ou seja, algo que encontraremos, mas do qual não sabemos, algo que diz de nós, mas fala além de nós, algo que, enfim, trai os pressupostos de nossas faculdades supostamente colocadas em concordância interna. Situamo-nos em uma experiência de travessia de uma viagem imóvel, pois esta se dá no plano das forças que nos habitam, às quais passamos a dar mais atenção do que às coisas propriamente ditas que se desenrolam aos nossos olhos. Estamos fora daquele mundo habitual perceptivo em que as portas giram em gonzos azeitados pelo bom senso e pelo senso comum. Já não podemos celebrar uma comunhão com a opinião, a qual impede a irrupção das ideias e do próprio pensar. Já estamos situados no fora de nossa familiaridade, estamos num estrangeiro, embora nem tenhamos saído de nossa localização física. Uma viagem para o Fora, que se poderia dizer também como uma viagem no tempo e não pelo espaço. Viagem esta que seria, enfim, a nossa passagem a um outro limiar estético, a uma nova forma de realidade dispersiva, errante e oscilante, operada por blocos com ligações fracas e acontecimentos flutuantes. Já nos situamos em um "mais de realidade", em que nossa percepção já não pode se prolongar em ação. Essa nova realidade que nos é dada permite-nos ver que o personagem tornou-se uma espécie de espectador que registra mais do que reage, estando entregue a uma visão, perseguido por ela ou perseguindo-a. As situações sensório-motoras aparecem enfraquecidas, dando lugar a um realismo com aspecto de sonho. Tudo permanece real neste realismo, porém, entre a realidade do meio e da ação não é mais um prolongamento motor que se estabelece, é antes uma relação onírica, por intermédio dos órgãos dos sentidos libertos, colocados em relação direta com o tempo, com o pensamento. Esta é, como nos fala Deleuze (2007), uma das características marcantes deste esteticismo visionário: a de tornar sensíveis o tempo e o pensamento, torná-los visíveis e sonoros. Cinema de vidente, não mais cinema de ação, que permite apreender algo inesquecível, imemorial e impensável. Não uma brutalidade como agressão nervosa, uma violência que sempre pode ser extraída das relações sensório-motoras do cinema-ação. Tampouco se trata de cenas de terror. Trata-se de algo poderoso demais ou injusto demais, mas às vezes também belo demais e que, portanto, excede nossas capacidades sensório-motoras. Tal caminho em direção a tornar-se visionário, faz da visão pura um meio de conhecimento e de ação e não é separável de uma revelação que opera como um terceiro olho.

Comumente, percebemos apenas clichês, ou seja, apenas temos uma imagem sensório-motora da coisa, imagem esta que se define sempre como subtração, uma vez que nossa percepção sempre atende ao que estamos interessados em perceber. Mas, se nossos esquemas sensoriais se bloqueiam ou quebram, se forem violentados, então pode aparecer um outro tipo de imagem, a ótico-sonora que faz surgir a coisa em si mesma, em seu excesso. É desta maneira que 
entendemos a obra de Bergman no plano do mundo do cinema: cinema de vidente que faz do movimento a perspectiva do tempo, constitui todo um cinema do tempo com a função de levar o olho à função de vidência, pois os elementos da imagem entram em relações que fazem com que a imagem inteira deva ser "lida" não menos que vista, legível tanto quanto visível. O mundo aparece para ser visto e lido, como literalidade. Cinema mais perto de uma leitura do que de uma percepção, cinema que nos leva ao caminho dos signos, que nos torna decifradores, nos faz recuar do reconhecimento automático e habitual.

\section{Referências}

BERGSON, H. Matéria e memória. São Paulo: Martins Fontes, 1990.

DELEUZE, G. Proust e os signos. Rio de Janeiro: Forense Universitária, 1987.

DELEUZE, G. Diferença e repetição. Rio de Janeiro: Graal, 1988.

DELEUZE, G. A Imagem-tempo. São Paulo: Brasiliense, 2007.

MORANGOS Silvestres. Direção: Ingmar Bergman. Filme (Preto/Branco, 95 min.). Suécia, 1957.

PROUST, M. Em busca do tempo perdido. Rio de Janeiro: Ediouro, 2004.

Submissão em: 30/11/2016

Aceite em: 10/04/2017

Tania Mara Galli Fonseca é psicóloga, mestre e doutora em Educação pela Universidade Federal do Rio Grande do Sul (UFRGS). Docente no Programa de Pós-graduação em Psicologia Social e Institucional (PPGPSI/UFRGS). Endereço: Rua Campos Sales, 262. Porto Alegre/ RS, Brasil CEP 90480-030. E-mail: tgallifonseca@gmail.com 